\title{
Caracterização molecular de Cryptosporidium spp. em bezerros (Bos taurus e Bos indicus) no município de Formiga, Minas Gerais - Brasil
}

\author{
Molecular characterization of Cryptosporidium spp. in calves (Bos \\ taurus and Bos indicus) in the Formiga city, Minas Gerais - Brazil
}

\author{
Roberto César Araujo Lima ${ }^{1 *}$; Monally Conceição Costa Aquino ${ }^{2}$; \\ Sandra Valéria Inácio ${ }^{2}$; Milena Araúz Viol²; Anaiza Simão Zucatto; \\ Luiz da Silveira Neto ${ }^{3}$; Bruno César Miranda Oliveira ${ }^{4}$ Edvânia Nunes Vasconcelos ${ }^{5}$; \\ Katia Denise Saraiva Bresciani ${ }^{6}$; Gilson Pereira Oliveira ${ }^{7}$; Alvimar José Costa ${ }^{8}$
}

\section{Resumo}

\begin{abstract}
A criptosporidiose, é a enfermidade de veiculação hídrica, possui como agravante a dificuldade de prevenção da contaminação ambiental e ausência de medidas terapêuticas eficazes. Com acentuada importância na bovinocultura, ocasiona inflamação e atrofia das vilosidades intestinais resultando em perda da superfície de absorção. Este estudo teve como objetivo realizar a caracterização molecular da infecção por Cryptosporidium spp. em bezerros do Município de Formiga, Minas Gerais. Um total de 300 amostras de fezes de bezerros holandeses, Nelore e sem raça definida saudáveis foram avaliadas pela técnica de coloração contraste negativo de verde malaquita e por meio da reação de Nested-PCR para amplificação de fragmentos de DNA da subunidade $18 \mathrm{~S}$ do gene do RNA ribossômico. Ocorrência de 5,33\% (16/300) pelo verde malaquita e 4,66\% (14/300), pela PCR foi observada, sendo que nenhuma correlação foi verificada entre a positividade e as variáveis estudadas. Por meio da caracterização molecular foram identificadas as espécies Cryptosporidium andersoni e Cryptosporidium ryanae. Como conclusão, observou-se baixa ocorrência da infecção e eliminação de oocistos por Cryptosporidium spp, ausência de sinais clínicos nos animais, houve forte concordância entre os resultados obtidos por meio das duas técnicas utilizadas e pela caracterização molecular (Nested-PCR) foram diagnosticadas as espécies C. andersoni e C. ryanae, presentes em faixas etárias não relatadas na literatura. Estas duas espécies de Cryptosporidium supracitadas são descritas pela primeira vez, parasitando bovinos no estado de Minas Gerais.
\end{abstract}

Palavras-chave: Criptosporidiose, identificação, PCR e/ou genotipagem, bovinos

\footnotetext{
Abstract

Cryptosporidiosis is a waterborne disease, has as aggravating the difficulty of preventing environmental contamination and lack of effective therapeutic measures. With marked importance to the cattle, causes

${ }^{1}$ Prof. Titular do Centro Universitário de Formiga, UNIFOR, Formiga, MG. E-mail: betolimavet@yahoo.com.br

${ }^{2}$ Discentes de Doutorado, Universidade Estadual Paulista, UNESP, Campus Araçatuba, Araçatuba, SP. E-mail: monallyaquino@, hotmail.com; sandra_byol@yahoo.com.br;milenaviol@hotmail.com; anaszucatto@hotmail.com

${ }^{3}$ Discente do Programa de Pós-Graduação em Medicina Veterinária, UNESP, Faculdade de Ciências Agrárias e Veterinárias, Jaboticabal, SP. E-mail: luiz.silveira@gmail.com

${ }^{4}$ Discente de Mestrado da UNESP, Campus Araçatuba, Araçatuba, SP. E-mail: brunocmo.vet@outlook.com

${ }^{5}$ Discente de Graduação da UNESP, Campus Araçatuba, Araçatuba, SP. E-mail: edvania.vet@gmail.com

${ }^{6}$ Prof A Adjunta da UNESP, Campus Araçatuba, Araçatuba, SP. E-mail: bresciani@fmva.unesp.br

${ }^{7}$ Prof. Dr. da UNESP, Campus Jaboticabal, Jaboticabal, SP. E-mail: gilsongpod@fcav.unesp.br

${ }^{8}$ Prof. Titular da UNESP, Campus Jaboticabal, Jaboticabal, SP. E-mail: cppar@asbyte.com.br

* Autor para correspondência
} 
inflammation and intestinal villous atrophy resulting in loss of absorptive surface. This study aimed to perform molecular characterization of Cryptosporidium spp. in calves in the city of Formiga, Minas Gerais. A total of 300 faeces samples from Holstein calves, Nelore and indefinite breed, both healthy, were evaluated by negative contrast staining technique of malachite green and through the reaction of nested PCR for amplification of DNA fragments of the 18S subunit of the RNA gene ribosomal. Occurrence of $5.33 \%$ ( $16 / 300$ ) for malachite green and $4.66 \%$ ( 14/300) by PCR was observed, whereas no correlation was found between positive and variables studied. Through molecular characterization were identified Cryptosporidium andersoni and Cryptosporidium ryanae species. In conclusion, we observed a low incidence of infection and elimination of Cryptosporidium spp. oocysts, the absence of clinical signs in animals, strong agreement between the results obtained by the two techniques. Beyond, with the molecular characterization ( nested PCR ), species of C. andersoni and C. ryanae were diagnosed in age groups not present in the literature. These two species of Cryptosporidium are described above for the first time parasitizing cattle in the state of Minas Gerais.

Key words: Cryptosporidiosis, identification, PCR, genotyping, cattle

\section{Introdução}

Os protozoários do gênero Cryptosporidium são parasitas intracelulares obrigatórios, capazes de se desenvolver nas microvilosidades das células epiteliais do trato gastrintestinal de hospedeiros vertebrados. Muitos animais de produção infectados por estes coccídios são assintomáticos ou apresentam diarréia aguda auto-limitante.

O Criptosporidium, Escherichia coli enteropatogênica, Rotavírus, Coronavirus e Salmonela são considerados importantes agentes etiológicos de diarréia em bezerros (HELMAN (2000) e podem atuar de maneira isolada ou estarem associados (RADOSTITS et al., 2000). A infecção criptosporídica é freqüentemente detectada durante as primeiras semanas de vida de ruminantes em síndromes diarréicos neonatais (FEITOSA et al., 2008).

Os métodos baseados em microscopia são os mais utilizados para o diagnóstico de rotina de infecções por Cryptosporidium spp. Em virtude da variação genética entre as espécies e genótipos de Cryptosporidium, é de fundamental importância a caracterização molecular de isolados em nosso país (MEIRELES, 2010).

Adultos e os bezerros desmamados são acometidos principalmente por Cryptosporidium andersoni, $C$. bovis e C. ryanae, já os lactentes são infectados por C. parvum e considerados como os maiores reservatórios desta espécie, que apresenta alto potencial zoonótico (XIAO, 2010).

O Brasil destacar-se por ser o terceiro maior produtor de leite e derivados e por possuir o segundo rebanho bovino do mundo. Neste contexto, O Estado de Minas Gerais (MG) apresenta a maior produção de leite e é o segundo maior criador de gado do País (IBGE, 2010).

No estado supramencionado, estudos constataram a ocorrência de Cryptosporidium por meio de técnicas parasitológicas específicas para a detecção deste parasito, mas sem a análise genética das espécies que infectam bezerros (SILVAJUNIOR et al., 2011).

Devido aos escassos trabalhos com caracterização molecular de Cryptosporidium spp em bezerros, em Minas Gerais e principalmente na região centro-oeste mineira, tendo em vista a importância da bovinocultura para economia deste estado na produção de carne e leite, objetivou-se diagnosticar a infecção de bezerros por método de observação direta em fezes e PCR, realizando-se também caracterização molecular de Cryptosporidium em bezerros da área rural do Município de Formiga, MG. 


\section{Material E Métodos}

\section{Locais e periodo}

As amostras foram colhidas em sete fazendas situadas em Formiga, no centro-oeste de Minas
Gerais (Fig. 1), durante o mês de julho de 2012. Este Município apresenta área aproximada de 1.502 $\mathrm{Km}^{2}$, com uma população de 65.128 habitantes, distante $195 \mathrm{~km}$ da capital Belo Horizonte (IBGE, 2013).

Figura 1. Mapa do Brasil e Minas Gerais, ampliado a cidade de Formiga com os sete pontos das propriedades.

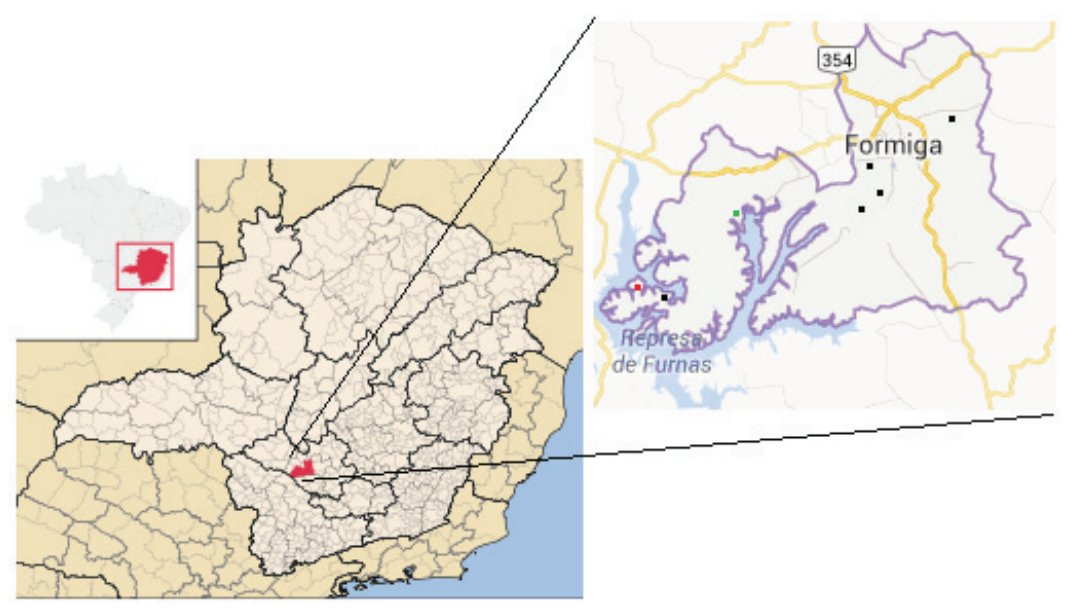

Fonte: Abreu (2006) Modificado.

\section{Animais utilizados}

Um total de 300 bezerros, saudáveis, de ambos os sexos, com idade entre 15 dias a 12 meses, de diferentes raças, sendo 100 holandeses, 100 Nelores e 100 não definidas (SRD).

Entre 1800 animais de um rebanho da raça Holandesa de uma grande propriedade, 400 eram bezerras e destas, 100 foram arroladas neste estudo com aptidão para leite. Esta fazenda tecnificada tinha produtividade diária média de sete mil litros de leite. Com monitoração semanal de médicosveterinários, o gado era periodicamente vermifugado e imunizado, sob regime de criação intensiva. $\mathrm{O}$ desmame das fêmeas era realizado aos três meses de idade, sendo que estas eram mantidas separadas por faixa etária em quatro piquetes. Após o período de aleitamento, era adicionada suplementação com concentrado protéico e energético, silo de milho, pasto de capim Tifton (Cynodon spp), sal mineral e água ad libitum de poços artesianos.

Os 100 animais sem raça definida (45 machos e 55 fêmeas) com aptidões mistas eram provenientes de criações pequenas (rebanhos com média de 10 a 50 animais), de pecuária familiar, com baixa tecnificação, sem assistência médico-veterinária, não sendo desverminados periodicamente e/ou vacinados. Estes seriam desmamados com mais de um ano de idade, momento em que as vacas cessassem a produção ou entrassem em trabalho de parto, sendo que o sistema de criação adotado era o semi-intensivo, com baixa suplementação de concentrado protéico e com pastagens diversificadas entre nativas e Braquiarão (Braquiaria brizantha).

Em um rebanho de 2000 bovinos Nelore com aptidão para corte com diferentes faixa etárias, com finalidade de cria e recria, haviam 400 bezerros 
e destes, 100 (45 fêmeas e 55 machos) foram envolvidos neste trabalho. A fazenda era pouco tecnificada, médicos veterinários eram responsáveis pelo controle reprodutivo, a desverminação era efetuada duas vezes por ano e eram vacinados contra raiva e clostridioses. O desmame acontecia aos oito meses de idade nesta propriedade, o sistema de manejo era extensivo, com pasto de Braquiarão (Brachiaria brizantha) e fontes de água nas vertentes das águas de furnas.

Para cada um dos bovinos foi confeccionada uma ficha epidemiológica, colhendo-se informações sobre as variáveis: raça, sexo, faixa etária (estimada em meses, de acordo com os registros dos proprietários dos animais), escore corporal, aleitamento e consistência fecal. O escore corporal foi estimado de acordo com Machado et al. (2008). As amostras fecais foram avaliadas quanto à consistência, sendo classificadas em diarréicas e não diarréicas. Os animais foram agrupados em relação aleitamento ou desmamados.

\section{Colheita e processamento das amostras}

As amostras fecais foram colhidas da ampola retal dos bezerros, foram armazenadas em sacos plásticos (identificados com a respectiva numeração de cada animal) e transportadas em caixas isotérmicas até o laboratório, onde foram processadas.

Inicialmente, foi efetuada a purificação e concentração das amostras de fezes. Estas foram divididas em duas alíquotas: a primeira delas foi acondicionada em potes coletores universais individuais contendo dicromato de potássio $2,5 \%$, sendo destinada à análise pelo método de verde malaquita e a outra foi congelada "in natura" a $-20^{\circ} \mathrm{C}$ até a execução da técnica de Nested-PCR.

Para a análise fecal, as lâminas foram observadas ao microscópio óptico em aumentos de 400 e 1000 vezes, após a realização da coloração negativa de Verde Malaquita (ELLIOT; MORGAN; THOMPSOM, 1999). Para a determinação da quantidade de oocistos por grama de fezes, um grama deste material foi diluído em $10 \mathrm{~mL}$ de solução de Tween $20(0,1 \%)$ com contagem posterior em camara de Neubauer (FEITOSA et al., 2008).

A Reação em Cadeira de Polimerase tipo Nested (Nested-PCR), seguida de sequenciamento dos fragmentos amplificados, foi realizada em todas as amostras positivas à coloração. Para amplificação de fragmentos do gene da subunidade $18 \mathrm{~S}$ do RNA ribossômico foi utilizada a técnica de Nested-PCR com os primers 5, TTC TAG AGC TAA TAC ATG CG 3' e 5' CCC ATT TCC TTC GAA ACA GGA 3' para a reação primária, com 1325 pares de base (pb) e 5' GGA AGG GTT GTA TTT ATT AGA TAA AG 3' e 5' AAG GAG TAA GGA ACA ACC TCC A 3' para a reação secundária, com 826 a 840 pb (XIAO et al., 2000). Nove amostras apresentavam amplificação intensa na eletroforese, posteriormente foi realizada a triplicata das mesmas e foi encaminhado o material para realização do seqüenciamento.

\section{Análise estatística}

A análise estatística descritiva foi efetuada por meio do cálculo de porcentagem e estatística inferencial pelo Teste Qui-Quadrado para verificar associação entre os resultados dos testes de diagnóstico empregados e as variáveis estudadas. O nível de significância adotado foi de $5 \%$ e as análises estatísticas foram efetuadas empregandose o programa SAS (1996) ("Statistical Analysis System”), versão 6.11.

\section{Resultados e Discussão}

A ocorrência de infecção por Cryptosporidium spp de acordo com as técnicas diagnósticas utilizadas de microscopia e PCR, conforme as variáveis estudadas, pode ser observada na Tabela 1. Ocorrência de 5,3\% (16/300) foi detectada pela técnica de contraste negativo de verde malaquita (Figura 1), resultados estes, inferiores aos 
encontrados por outras técnicas de microscopia (WANG, et al., 2011, SAFAVI; MOHAMMADI; NAGHIBI, 2012).

Pela Nested-PCR verificou-se uma ocorrência de 4,6\% (14/300), demonstrando quantidade menor de amostras positivas em relação à técnica de coloração. Porcentagens de positividade superiores à evidenciada neste estudo, foram detectadas (FOLLET, et al., 2011; MURAKOSHI, et al., 2012).

Entre os fatores de risco analisados, nenhum deles apresentou correlação com a positividade para Cryptosporidium spp, conforme descrito na Tabela 1. Esta ausência de correlação com a criptosporidiose contrasta com resultados que verificaram que o sistema de criação intensivo e a raça são fatores preponderantes para maior ocorrência desta coccidiose (MARTINS-VIEIRA; BRITO; HELLER, 2009).

Todos os animais infectados tinham fezes com consistência não diarréica, sugerindo que a positividade para Cryptosporidium spp, não teve correlação com a consistência das fezes e que estes bezerros são portadores e potenciais transmissores desta enfermidade.

Neste estudo foram identificados e quantificados os oocistos de Cryptosporidium spp., demonstrando que dez entre os 16 apresentavam apenas um oocisto por lâmina, demonstrando a escassa liberação de oocistos. Isto também foi observado pela a técnica de Sheather em bezerros acima de 15 dias de idade (FEITOSA et al., 2008). A utilização de técnicas moleculares para a confirmação do diagnóstico é especialmente recomendada em casos em que existam poucos oocistos nas fezes ou dúvidas (MEIRELES, 2010).

Dentre as nove amostras sequenciadas, seis foram caracterizadas como C. ryanae, sendo esta espécie encontrada nas faixas etárias entre dois e oito meses de idade, em todos os grupos raciais estudados (SRD, Holandesa e Nelore). Três amostras eram $C$. andersoni, sendo encontrados apenas nos animais SRD, com idade entre seis e oito meses. Adicionalmente, foram evidenciadas mais sete amostras não amplificadas citadas como Cryptosporidium spp (Figura 2), conforme descrito na Tabela 2.

Figura 2. Aspecto microscópio de oocistos de Cryptosporidium spp em esfregaços fecais de bezerros corados em coloração negativa de verde malaquita (setas).

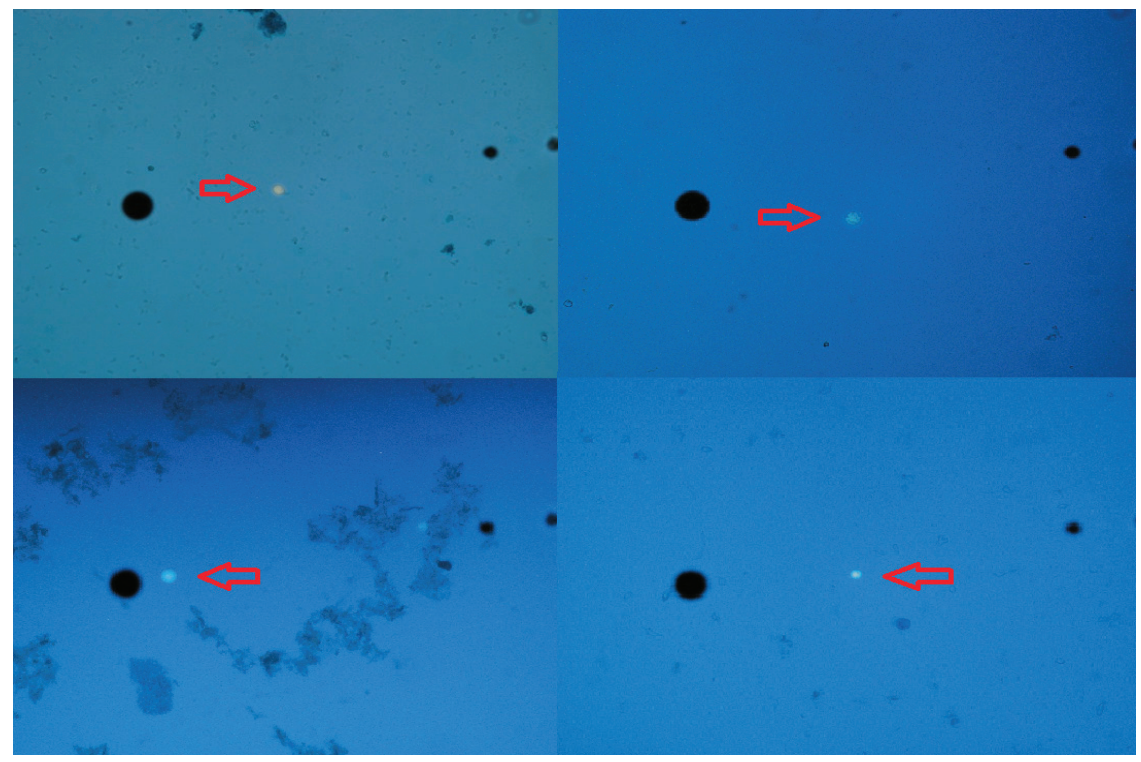

Fonte: Elaboração dos autores. 
As infecções por C. ryanae e C.andersoni velhos, acima de 14 semanas com menor número em bezerros destas faixas etárias (Tabela 2) de animais positivos principalmente quando os representam achados incomuns e estas observações animais tem maior faixa etária. Nestes trabalhos corroboram com os estudos de Murakoshi, et anteriormente citados, não foi constatada relação al., 2012. A maioria dos casos de infecção por estas duas espécies, ocorrem em bezerros mais entre diarréia e positividade para Cryptosporidium spp.

Tabela 1 Ocorrência da infecção por Cryptosporidium spp, pela técnica de microscopia com contraste negativo com verde malaquita e pela PCR, conforme o grupo racial, sexo, idade, escore corporal, consistência e coloração fecal, em bovinos jovens de cinco propriedades rurais do município de Formiga, MG, 2012.

\begin{tabular}{|c|c|c|c|c|c|c|c|}
\hline \multirow{3}{*}{ Variável } & \multirow{3}{*}{ Categoria } & \multirow{3}{*}{$\begin{array}{c}\mathrm{N}^{\mathrm{o}} \text { de } \\
\text { bovinos }\end{array}$} & \multicolumn{4}{|c|}{ Técnicas } & \multirow{3}{*}{$\begin{array}{l}\text { Valor de } p \\
\text { teste } \chi^{2}\end{array}$} \\
\hline & & & \multicolumn{2}{|c|}{ CNVM } & \multicolumn{2}{|c|}{ PCR } & \\
\hline & & & Positivo & $\%$ & Positivo & $\%$ & \\
\hline \multirow{3}{*}{ Grupo racial } & SRD & 100 & 5 & 5,00 & 5 & 5,00 & \multirow{3}{*}{$\begin{array}{l}0,2852^{(1)} \\
0,2409^{(2)}\end{array}$} \\
\hline & Nelore & 100 & 3 & 3,00 & 2 & 2,00 & \\
\hline & Holandês & 100 & 8 & 8,00 & 7 & 7,00 & \\
\hline \multirow{6}{*}{$\begin{array}{l}\text { Idade } \\
\text { (meses) }\end{array}$} & $0,5-2$ & 62 & 2 & 3,22 & 2 & 3,22 & \multirow{6}{*}{$\begin{array}{l}0,4794^{(1)} \\
0,3848^{(2)}\end{array}$} \\
\hline & $3-4$ & 55 & 4 & 7,27 & 3 & 5,45 & \\
\hline & $5-6$ & 64 & 5 & 7,81 & 5 & 7,81 & \\
\hline & $7-8$ & 50 & 3 & 6,00 & 3 & 6,00 & \\
\hline & $9-10$ & 50 & 1 & 2,00 & 0 & 0,00 & \\
\hline & $11-12$ & 19 & 1 & 5,26 & 1 & 5,26 & \\
\hline \multirow{5}{*}{$\begin{array}{c}\text { Escore } \\
\text { Corporal } \\
(1-5)\end{array}$} & 2,0 & 9 & 0 & 0,00 & 0 & 0,00 & \multirow{5}{*}{$\begin{array}{l}0,8978^{(1)} \\
0,9818^{(2)}\end{array}$} \\
\hline & 2,5 & 68 & 4 & 5,88 & 4 & 5,88 & \\
\hline & 3,0 & 115 & 6 & 5,21 & 5 & 4,34 & \\
\hline & 3,5 & 55 & 0 & 0,00 & 0 & 0,00 & \\
\hline & 4,0 & 53 & 6 & 11,32 & 5 & 9,43 & \\
\hline \multirow{2}{*}{ Aleitamento } & Com & 160 & 8 & 5,00 & 8 & 5,00 & \multirow{2}{*}{$\begin{array}{l}0,7836^{(1)} \\
0,7698^{(2)}\end{array}$} \\
\hline & Sem & 140 & 8 & 5,71 & 6 & 4,28 & \\
\hline \multirow{2}{*}{ Consistência } & Diarréica & 7 & 0 & 0,00 & 0 & 0,00 & \multirow{2}{*}{$\begin{array}{l}0,5516^{(1)} \\
0,4642^{(2)}\end{array}$} \\
\hline & Não diarréica & 293 & 16 & 5,46 & 14 & 4,77 & \\
\hline \multirow{5}{*}{ Sexo } & SRD M & 45 & 1 & 2,22 & 1 & 2,22 & \multirow{5}{*}{$\begin{array}{l}0,2038^{(1)} \\
0,2518^{(2)}\end{array}$} \\
\hline & SRD F & 55 & 4 & 7,27 & 4 & 7,27 & \\
\hline & Nelore $\mathbf{M}$ & 55 & 0 & 0,00 & 0 & 0,00 & \\
\hline & Nelore $\mathbf{F}$ & 45 & 3 & 6,66 & 2 & 4,44 & \\
\hline & Holandês F & 100 & 8 & 8,00 & 7 & 7,00 & \\
\hline
\end{tabular}

(1) Malaquita; (2) PCR; M: machos; F: Fêmeas

CNVM: Contraste Neg. Verde Malaquita; PCR: Reação em cadeia da polimerase;

$N^{o}$ : Número de animais examinados; $p \geq 0,05$ : Não significativo; $p \leq 0,05$ Significativo estatisticamente.

Fonte: Elaboração dos autores. 
Tabela 2 Distribuição das espécies de Cryptosporidium de acordo com a faixa etária dos animais, em bovinos jovens de cinco propriedades rurais do município de Formiga, MG, 2012.

\begin{tabular}{|c|c|c|c|}
\hline Faixa etária (meses) & $\mathbf{N}^{0}$ & Raças & Espécies de Cryptosporidium ${ }^{\mathrm{a}}$ ( $\mathrm{N}^{0}$ animais) \\
\hline $0,5-2$ & 62 & Holandesa & C. ryanae (2) \\
\hline $3-4$ & 55 & $\begin{array}{c}\text { SRD } \\
\text { Holandesa }\end{array}$ & $\begin{array}{r}\text { C. ryanae (1) } \\
\text { Cryptosporidium spp (3) }\end{array}$ \\
\hline $5-6$ & 64 & $\begin{array}{c}\text { Nelore e SRD } \\
\text { Holandesa } \\
\text { SRD }\end{array}$ & $\begin{array}{r}\text { C. ryanae (2) } \\
\text { Cryptosporidium spp. (2) } \\
\text { C. andersoni (1) }\end{array}$ \\
\hline $7-8$ & 50 & $\begin{array}{l}\text { Nelore } \\
\text { SRD }\end{array}$ & $\begin{array}{r}\text { C. ryanae (1) } \\
\text { C. andersoni (2) }\end{array}$ \\
\hline $9-10$ & 50 & Nelore & Cryptosporidium spp (1) \\
\hline $11-12$ & 19 & Holandesa & Cryptosporidium spp (1) \\
\hline Total & 300 & & $\begin{array}{r}\text { C. ryanae (6) } \\
\text { Cryptosporidium spp (5) } \\
\text { C. andersoni (3) }\end{array}$ \\
\hline
\end{tabular}

a - A identificação das espécies foi realizada apenas em amostras que apresentaram amplificação do DNA.

Fonte: Elaboração dos autores.

Figura 2. Amplificação intensa na eletroforese em triplicata para realização do sequenciamento de Cryptosporidium spp

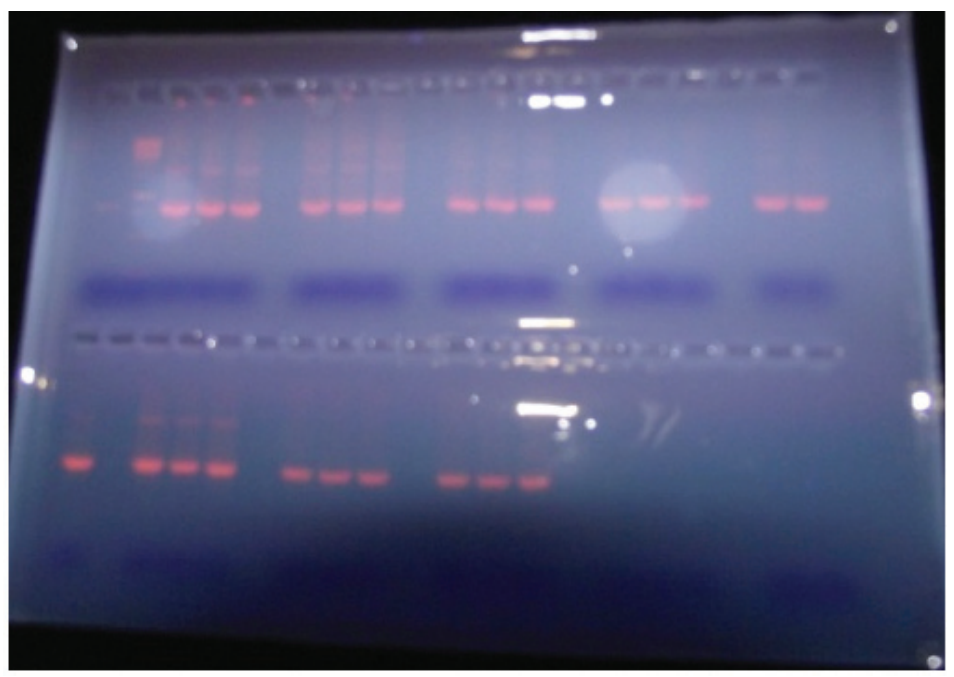

Fonte: Elaboração dos autores.

\section{Conclusão}

A partir dos resultados obtidos neste estudo, pode-se inferir que se observou baixa ocorrência da infecção por Cryptosporidium spp, ausência de sinais clínicos nos animais, houve forte concordância entre os resultados obtidos por meio das duas técnicas utilizadas e pela caracterização molecular (Nested-PCR) foram diagnosticadas as espécies C. andersoni e C. ryanae, presentes em faixas etárias não relatadas na literatura. Estas duas espécies supracitadas são descritas pela 
primeira vez, parasitando bovinos no estado de Minas Gerais.

\section{Referências}

ABREU, R. L. Mapa da cidade de Formiga MG. [S.1: s.n.], 2006.

ELLIOT, A.; MORGAN, U. M.; THOMPSOM, R. C. A. Improved staining method for detecting Cryptosporidium oocysts in stools using malachite green. Journal of General and Applied Microbiology, v. 45, p. 139-142, 1999.

FEITOSA, T. F.; SHIMAMURA, G. M.; ROBERTO, T.; MENDES, L. C. N.; PEIRÓ, J. R.; FÉRES, F. C.; BOVINO, F.; PERRI, S. V. P.; MEIRELES, M. V. Importância de Cryptosporidium spp. como causa de diarréia em bezerros. Pesquisa Veterinária Brasileira, Seropédica, v. 28, n. 10, p. 452-456, 2008.

FOLLET, J.; GUYOT, K.; LERUSTE, H.; FOLLETDUMOULIN, A.; HAMMOUMA-GHELBOUN, O.; CERTAD, G.; DEI-CAS, E.; HALAMA, P. Cryptosporidium infection in a veal calf cohort in France: molecular characterization of species in a longitudinal study. Veterinary Research, Ghent, v. 42, p. 116, 2011.

HELMAN, R. G. Diagnosis of diseases of the digestive tract. The Veterinary Clinics of North America: Food Anmal Practice, Philadelphia, v. 16, n. 1, p. 50-54, 2000.

INSTITUTO BRASILEIRO DE GEOGRAFIA E ESTATSTICA-IBGE.Informações estatísticasdeformiga - Minas Gerais. 2013. Disponível em: <http://cidades. ibge.gov.br/xtras/perfil.php?lang $=\&$ codmun $=312610>$. Acesso em: 16 out. 2013.

Produção da pecuária municipal. v. 38, 2010. 65 p. Disponível em: <http://www.ibge.gov.br/home/ estatistica/economia/ppm/2010/ppm2010.pdf $>$. Acesso em: 16 out. 2013.

MACHADO, R.; CORREAA, R. F.; BARBOSA, R. T.; BERGAMASCHI, M. A. Escore da condição corporal e sua aplicação no manejo reprodutivo de ruminantes. São Carlos, SP: Embrapa Pecuária Sudeste, 2008. dez. 16 p. (Circular Técnica Embrapa, v. 57).

MARTINS-VIEIRA, M. B. C.; BRITO, L. A. L.; HELLER, L. Oocistos de Cryptosporidium parvum em fezes de bezerro infectado experimentalmente. Arquivo Brasileiro de Medicina Veterinária e Zootecnia, Belo Horizonte, v. 61, n. 6, p. 1454-1458, 2009.
MEIRELES, M. V. Cryptosporidium infection in Brazil: implications for veterinary medicine and public health. Revista Brasileira de Parasitologia, São Paulo, v. 19, n. 4, p. 197-204, 2010.

MURAKOSHI, F.; XIAO, L.; MATSUBARA, R.; SATO, R.; KATO, Y.; SASAKI, T.; FUKUDA, Y.; TADA, C.; NAKAI, Y. Molecular characterization of Cryptosporidium spp. in grazing beef cattle in Japan. Veterinary Parasitology, Amsterdam, v. 187, n. 1-2, p. 123-128, 2012.

RADOSTITS, O. M.; GAY, C. C.; BLOOD, D. C.; HINCHCLIFF, K. W. Doenças causadas pelos protozoários. In:_. Clínica veterinária: um tratado de doenças dos bovinos, ovinos, suínos, caprinos e eqüinos. 9. ed. Rio de Janeiro: Guanabara Koogan, 2000. cap. 25, p. 1156-1194.

SAFAVI, E. A.; MOHAMMADI, G. R.; NAGHIBI, A.; RAD, M. Prevalence of Cryptosporidium spp. infection in some dairy herds of Mashhad (Iran) and its association with diarrhea in newborn calves. Comparative Clinical Pathology, v. 20, n. 2, p. 103-107, 2012.

SAS INSTITUTE. SAS/STAT. User's guide. version 6.11. v. 2, Cary: SAS Institute Inc., 1996. 842 p.

SILVA-JÚNIOR, F. A.; CARVALHO, A. H. O.; ROCHA, C. M. B. M.; GUIMARÃES, A. M. Fatores de risco associados à infecção por Cryptosporidium spp. e Giardia duodenalis em bovinos leiteiros na fase de cria e recria na mesorregião do Campo das Vertentes de Minas Gerais. Pesquisa Veterinária Brasileira, Seropédica, v. 31, n. 8, p. 690-696, 2011.

WANG, R.; WANG, H.; SUN, Y.; ZHANG, L.; JIAN, F.; QI, M.; NING, C. E.; XIAO, L. Characteristics of Cryptosporidium transmission in preweaned dairy cattle in Henan, China. Journal of Clinical Microbiology, Barcelona, v. 49, n. 3, p. 1077-1082, mar. 2011.

XIAO, L. Molecular epidemiology of cryptosporidiosis: An update. Experimental Parasitology, v. 124, n. 1, p. $80-89,2010$

XIAO, L.; ALDERISIO, K.; LIMOR, J.; ROYER, M.; LAL, A. A. Identification of species and sources of Cryptosporidium oocysts in storm waters with a smallsubunit rRNA-based diagnostic and genotyping tool. Applied and Environmental Microbiology, Washington D.C, v. 66, n. 12, 5492-5498, 2000. 